Article

\title{
Simultaneous Thermal Stability and Ultrahigh Sensitivity of Heterojunction SERS Substrates
}

\author{
Lingwei Ma ${ }^{1}$, Jinke Wang ${ }^{1}$, Hanchen Huang ${ }^{2, *}$, Zhengjun Zhang ${ }^{3, *(\mathbb{D},}$, Xiaogang $\mathrm{Li}^{1}$ and Yi Fan ${ }^{4}$ \\ 1 Institute of Advanced Materials \& Technology, University of Science and Technology Beijing, \\ Beijing 100083, China; mlw1215@ustb.edu.cn (L.M.); wjkgege@126.com (J.W.); lixiaogang@ustb.edu.cn (X.L.) \\ 2 College of Engineering, University of North Texas, Denton, TX 76207, USA \\ 3 Key Laboratory of Advanced Materials, School of Materials Science and Engineering, Tsinghua University, \\ Beijing 100084, China \\ 4 Jiangsu Key Laboratory for Premium Steel Material, Nanjing Iron and Steel Co., Ltd., Nanjing 210035, China; \\ fanyi@njsteel.com.cn \\ * Correspondence: Hanchen.Huang@unt.edu (H.H.); zjzhang@tsinghua.edu.cn (Z.Z.)
}

Received: 5 May 2019; Accepted: 21 May 2019; Published: 31 May 2019

\begin{abstract}
This paper reports the design of $\mathrm{Ag}-\mathrm{Al}_{2} \mathrm{O}_{3}-\mathrm{Ag}$ heterojunctions based on $\mathrm{Ag}$ nanorods (AgNRs) and their applications as thermally stable and ultrasensitive substrates of surface-enhanced Raman scattering (SERS). Specifically, an ultrathin $\mathrm{Al}_{2} \mathrm{O}_{3}$ capping layer of $10 \mathrm{~nm}$ on top of AgNRs serves to slow down the surface diffusion of Ag at high temperatures. Then, an additional Ag layer on top of the capping layer creates $\mathrm{AgNRs}-\mathrm{Al}_{2} \mathrm{O}_{3}-\mathrm{Ag}$ heterojunctions, which lead to giant enhancement of electromagnetic fields within the $\mathrm{Al}_{2} \mathrm{O}_{3}$ gap regions that could boost the SERS enhancement. As a result of this design, the SERS substrates are thermally stable up to $200{ }^{\circ} \mathrm{C}$, which has been increased by more than $100{ }^{\circ} \mathrm{C}$ compared with bare AgNRs, and their sensitivity is about $400 \%$ that of pure AgNRs. This easy yet effective capping approach offers a pathway to fabricate ultrasensitive, thermally stable and easily prepared SERS sensors, and to extend SERS applications for high-temperature detections, such as monitoring in situ the molecule reorientation process upon annealing. Such simultaneous achievement of thermal stability and SERS sensitivity represents a great advance in the design of SERS sensors and will inspire the fabrication of novel hetero-nanostructures.
\end{abstract}

Keywords: surface-enhanced Raman scattering (SERS); glancing angle deposition (GLAD); heterojunctions; SERS sensitivity; thermal stability

\section{Introduction}

Surface-enhanced Raman scattering (SERS) is the foundation of a powerful spectroscopic technique for rapid and non-destructive determination of chemical [1], environmental [2,3] and biological [4] analytes at trace levels, even at the level of a single molecule [5]. To achieve high sensitivity of SERS, the substrates are typically nanoscale noble metals, such as $\mathrm{Ag}$, $\mathrm{Au}$, and $\mathrm{Cu}$, that have superior plasmonic efficiency [6,7]. While the nanoscale dimension gives rise to high sensitivity, it also leads to thermal instability because nanostructures coarsen easily at elevated temperatures [8,9]. For example, Ag nanorods (AgNRs) array and Ag colloids coarsen so much that they fuse at a temperature as low as $50{ }^{\circ} \mathrm{C}[10,11]$, thus limiting their practical SERS applications, such as monitoring in situ the thermal crystallization and the catalysis process.

Aiming to preserve the high sensitivity and yet to achieve thermal stability of SERS substrates, we have recently proposed and demonstrated the capping of AgNRs using high-melting temperature $\mathrm{Al}_{2} \mathrm{O}_{3}$ [12]. In contrast to oxide coating that also improves thermal stability [13-16], the oxide capping minimizes the reduction of exposed metallic surfaces that provide SERS sensitivity. A capping layer 
of $10 \mathrm{~nm} \mathrm{Al} \mathrm{O}_{3}$ gives an optimal combination of thermal stability up to $200{ }^{\circ} \mathrm{C}$ and slight reduction of sensitivity by $25 \%$ [12]. The improved thermal stability opens the door for SERS applications in high-temperature environments. However, high-temperature SERS sensing often involves the detection of monolayer molecular adsorption and interface interactions [17-19], and therefore requires ultrahigh sensitivity. While preserving the improved thermal stability, is it possible to increase the sensitivity by $100 \%$ or more?

To achieve this goal, we propose the design of $\mathrm{Ag}-\mathrm{Al}_{2} \mathrm{O}_{3}-\mathrm{Ag}$ heterojunctions based on $\mathrm{AgNRs}$. As conceptually illustrated in Figure 1, we first deposit AgNRs and cap them with $\mathrm{Al}_{2} \mathrm{O}_{3}$ layers, and then deposit additional Ag of optimal thickness. The $\mathrm{AgNRs}-\mathrm{Al}_{2} \mathrm{O}_{3}-\mathrm{Ag}$ heterojunctions give rise to giant electromagnetic (EM) enhancement [20], which in turn leads to ultrahigh SERS sensitivity [21,22]. In this paper, we demonstrate the feasibility of this proposal using the glancing angle deposition (GLAD) technique $[10,12]$. Our experiments show that the proposed design leads to thermal stability up to $200{ }^{\circ} \mathrm{C}$ and SERS sensitivity up to $400 \%$ that of pure AgNRs. The SERS intensity of different AgNRs- $\mathrm{Al}_{2} \mathrm{O}_{3}-\mathrm{Ag}$ substrates first elevates with the $\mathrm{Ag}$ capping thickness, reaches a maximum at the $\mathrm{Ag}$ thickness of $150 \mathrm{~nm}$, and declines beyond the critical thickness. The Raman signal of methylene blue (MB) is clearly measurable on the $\mathrm{Ag}-10 \mathrm{Al}_{2} \mathrm{O}_{3}-150 \mathrm{Ag}$ substrate, even at a low concentration of $1 \times 10^{-10} \mathrm{M}$. The SERS enhancement factor is on the order of $10^{8}$, which is comparable to the best reported results of AgNRs-based substrates [23-25], and the stable temperature of $\mathrm{AgNRs}-\mathrm{Al}_{2} \mathrm{O}_{3}-\mathrm{Ag}$ increases by more than $100{ }^{\circ} \mathrm{C}$. As a straightforward application of the heterojunctions, we exploit them to characterize the reorientation process of 4-tert-butylbenzylmercaptan (4-tBBM) molecules at elevated temperatures.
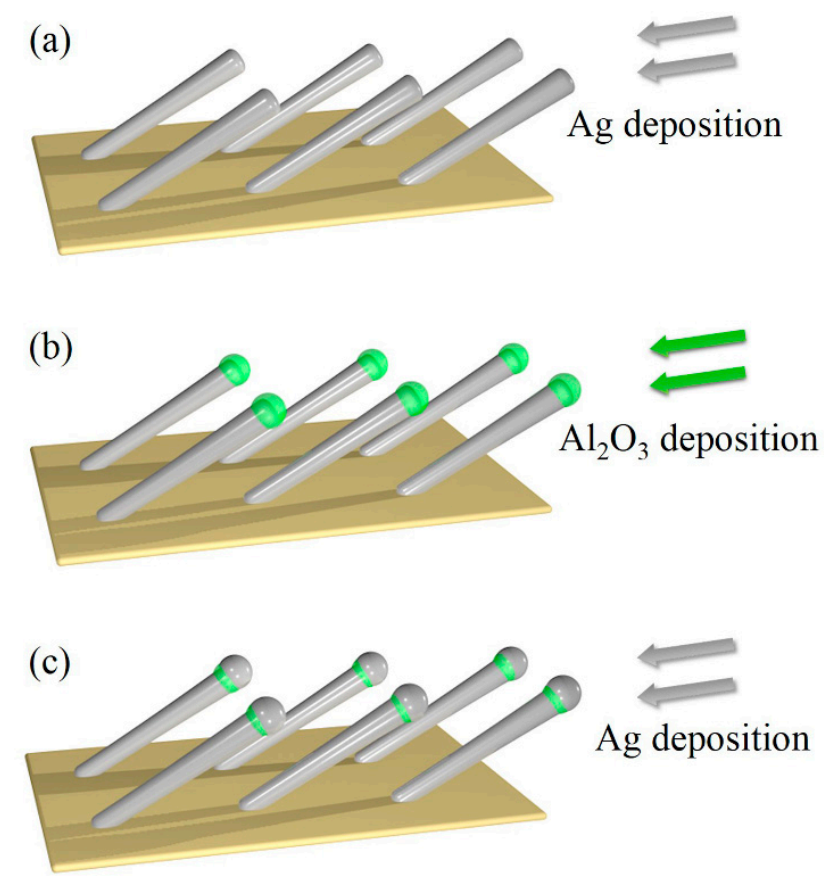

Figure 1. Schematic of (a) AgNRs deposition, (b) capping of AgNRs with $\mathrm{Al}_{2} \mathrm{O}_{3}$, (c) deposition of additional Ag.

\section{Materials and Methods}

\subsection{Fabrication and Thermal Annealing of $\mathrm{AgNRs}-\mathrm{Al}_{2} \mathrm{O}_{3}-\mathrm{Ag}$ Substrates}

AgNRs are deposited on $\mathrm{Si}$ (001) substrates using the GLAD technique in an electron-beam system with a background vacuum level down to $10^{-5} \mathrm{~Pa}$. During deposition, the incident angle of the vapor flux is set at $86^{\circ}$ off the substrate normal. The nominal deposition rate is fixed at $0.75 \mathrm{~nm} / \mathrm{s}$. The nominal rate refers to the rate with zero-degree incidence angle, as read by a quartz crystal microbalance (QCM). 
The total nominal deposition is $1000 \mathrm{~nm}$ in thickness. After the deposition of AgNRs, without breaking the vacuum, the target is switched to $\mathrm{Al}_{2} \mathrm{O}_{3}$ in the deposition chamber. The incidence angle is set at $86^{\circ}$ and the deposition rate is $0.1 \mathrm{~nm} / \mathrm{s}$. Our choice of $\mathrm{Al}_{2} \mathrm{O}_{3}$ thickness is based on the following two considerations. First, $\mathrm{Al}_{2} \mathrm{O}_{3}$ thickness needs to be sufficiently small to avoid the excessive coverage of Ag surfaces. Second, it needs to be large enough to maximize the thermal stability. The detailed optimization process of $\mathrm{Al}_{2} \mathrm{O}_{3}$ thickness is discussed in the Supporting Information (see Figures S1-S4). On the one hand, the SERS efficiency of $\mathrm{AgNRs}-\mathrm{Al}_{2} \mathrm{O}_{3}$ substrates with $6 \mathrm{~nm}$ to $12 \mathrm{~nm}$ capping declined moderately with $\mathrm{Al}_{2} \mathrm{O}_{3}$ deposition. On the other hand, by depositing $10 \mathrm{~nm}$ or thicker $\mathrm{Al}_{2} \mathrm{O}_{3}$ onto AgNRs, the substrates exhibited no discernible morphology variation at $200{ }^{\circ} \mathrm{C}$. Therefore, the total nominal deposition thickness of $\mathrm{Al}_{2} \mathrm{O}_{3}$ we used in this work is $10 \mathrm{~nm}$ [12].

Finally, the evaporation target is switched to Ag again in the chamber, the incident angle is kept at $86^{\circ}$, and the deposition rate is decreased to $0.3 \mathrm{~nm} / \mathrm{s}$ for better coverage of the $\mathrm{Al}_{2} \mathrm{O}_{3}$. The total nominal deposition of $\mathrm{Ag}$ is set as 20,50,100, 125, 150, 175 and $200 \mathrm{~nm}$, respectively, for each test. The AgNRs- $\mathrm{Al}_{2} \mathrm{O}_{3}-\mathrm{Ag}$ substrates are annealed on a hot plate at each given temperature for $15 \mathrm{~min}$ in air. The morphology evolution process during annealing is monitored in situ via the reflectivity variations, using the Optical Power Thermal Analyzer (OPA-1200, Wuhan Joule Yacht Science \& Technology Co., Ltd., Wuhan, China).

\subsection{Characterizations of $\mathrm{AgNRs}-\mathrm{Al}_{2} \mathrm{O}_{3}-\mathrm{Ag}$ Substrates - Morphology, Structure, and SERS}

The morphology and structure of the prepared SERS substrates are characterized using a scanning electron microscope (SEM, JEOL-JMS-7001F, Tokyo, Japan) and a high-resolution transmission electron microscope (HRTEM, JEOL-2011, Tokyo, Japan). SERS performance is characterized using an optical fiber micro-Raman system (i-Raman Plus, B\&W TEK Inc., Newark, DE, United States), with MB and 4-tBBM as probing molecules. Raman spectra are collected based on an excitation laser of $785 \mathrm{~nm}$ in wavelength and of $100 \mathrm{~mW}$ in power, with a beam spot of $\sim 80$ microns in diameter. Before SERS characterizations, all substrates are immersed into analyte solutions for $30 \mathrm{~min}$, washed thoroughly by deionized water to remove the residual molecules, and are then dried naturally in air. The data collection time for each spectrum is set to be five seconds and each SERS spectrum is obtained by measuring and averaging the signals collected from five different spots on a substrate.

\subsection{FEM Simulation}

Numerical simulations of $\mathrm{AgNRs}, \mathrm{AgNRs}-\mathrm{Al}_{2} \mathrm{O}_{3}$ and $\mathrm{AgNRs}-\mathrm{Al}_{2} \mathrm{O}_{3}-\mathrm{Ag}$ were conducted using the finite element method (FEM) software COMSOL Multiphysics 5.2. Dimensional parameters were acquired from SEM observations, together with the excitation wavelength of $785 \mathrm{~nm}$.

\section{Results and Discussion}

As the first set of results, we present the SEM and HRTEM images of $\mathrm{AgNRs}-\mathrm{Al}_{2} \mathrm{O}_{3}-\mathrm{Ag}$ arrays of various $\mathrm{Ag}$ deposition thickness on top of $\mathrm{AgNRs}-\mathrm{Al}_{2} \mathrm{O}_{3}$. As shown in Figure 2, the additional deposition of $50 \mathrm{~nm} \mathrm{Ag}$ leads to the formation of Ag nanoparticles. As the deposition thickness increases to $100 \mathrm{~nm}$, these nanoparticles merge to cover the $\mathrm{Al}_{2} \mathrm{O}_{3}$ capping. The coverage is more complete as the thickness increases to $150 \mathrm{~nm}$. Further increase of the thickness to $200 \mathrm{~nm}$ results in the bridging of neighboring nanorods. Therefore, moderate thickness of deposition, around $150 \mathrm{~nm}$, leads to the heterojunctions that we conceptually proposed in Figure 1. 

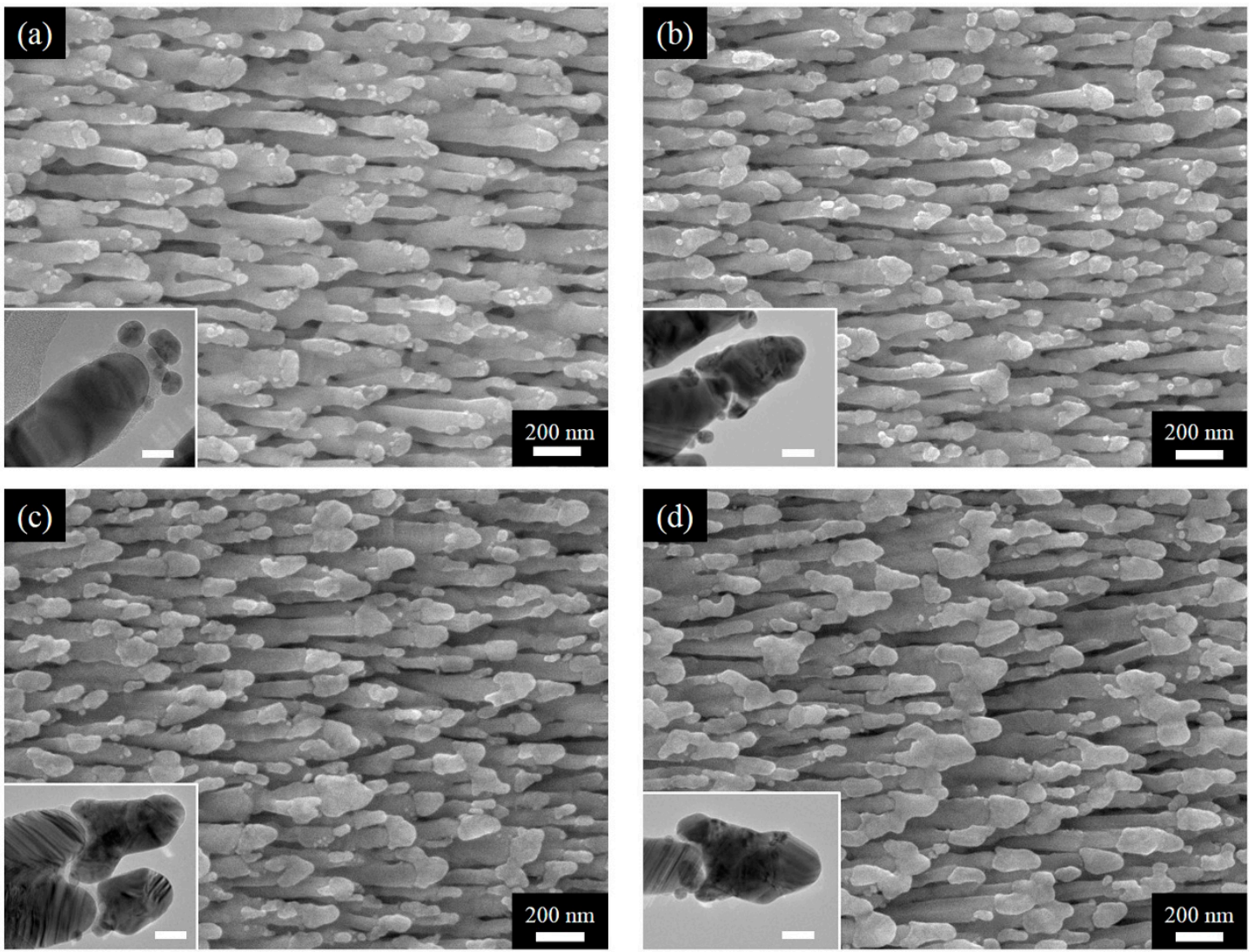

Figure 2. SEM images of $\mathrm{AgNRs}-\mathrm{Al}_{2} \mathrm{O}_{3}-\mathrm{Ag}$ arrays with additional $\mathrm{Ag}$ deposition of (a) $50 \mathrm{~nm}$, (b) $100 \mathrm{~nm}$, (c) $150 \mathrm{~nm}$, and (d) $200 \mathrm{~nm}$; accompanying HRTEM images are included as insets with the scale bar being $20 \mathrm{~nm}$.

Next, we examine the SERS sensitivity of $\mathrm{AgNRs}-\mathrm{Al}_{2} \mathrm{O}_{3}-\mathrm{Ag}$ arrays. Figure 3a shows the SERS spectra of $1 \times 10^{-6} \mathrm{M} \mathrm{MB}$ [26] on AgNRs- $\mathrm{Al}_{2} \mathrm{O}_{3}$ - $\mathrm{Ag}$ arrays with various thickness of additional $\mathrm{Ag}$ deposition in the final stage. The spectrum on the AgNRs substrate is included for comparison. Characteristic Raman peaks are clearly seen in Figure 3a. In-plane bending of $\mathrm{C}-\mathrm{H}$ is observed at $772 \mathrm{~cm}^{-1}, 886 \mathrm{~cm}^{-1}$, and $1040 \mathrm{~cm}^{-1}$, and in-plane ring mode of $\mathrm{C}-\mathrm{H}$ is at $1300 \mathrm{~cm}^{-1} .1181 \mathrm{~cm}^{-1}$ is assigned to the stretching of $\mathrm{C}-\mathrm{N}$. Besides, $1396 \mathrm{~cm}^{-1}, 1435 \mathrm{~cm}^{-1}$ and $1622 \mathrm{~cm}^{-1}$ correspond to the symmetric and asymmetric $\mathrm{C}-\mathrm{N}$ stretches, as well as the $\mathrm{C}-\mathrm{C}$ ring stretching, respectively. Indeed, the additional deposition of Ag increases the sensitivity, and an optimal amount is around $150 \mathrm{~nm}$, consistent with the heterojunction morphology that is shown in Figure 2. Taking the characteristic peak at $1622 \mathrm{~cm}^{-1}$ as reference, Figure $3 \mathrm{~b}$ shows the Raman intensity, normalized by that on bare AgNRs, as a function of the additional thickness of Ag deposition. The SERS intensity of different AgNRs- $\mathrm{Al}_{2} \mathrm{O}_{3}-\mathrm{Ag}$ substrates first elevates with the $\mathrm{Ag}$ capping thickness, reaches a maximum at the Ag thickness of $150 \mathrm{~nm}$, and declines beyond the critical thickness. This sensitivity variation trend can be explained by different Ag morphologies: As Ag thickness increases, Ag layers grow from small particles into complete capping over nanorod tips, which could generate stronger EM field in the gap regions. When the deposition thickness exceeds $150 \mathrm{~nm}, \mathrm{Ag}$ capping coalesces into large aggregations without clear tips and gaps, in which way the SERS activity declines to some extent. Remarkably, with the optimal Ag deposition thickness of $150 \mathrm{~nm}$, the intensity (and thereby sensitivity) is about $400 \%$ that on bare AgNRs. For better comparison, we prepared two reference substrates, i.e., AgNRs coated with $150 \mathrm{~nm} \mathrm{Ag}$ (AgNRs-150Ag) and $10 \mathrm{~nm} \mathrm{Al}{ }_{2} \mathrm{O}_{3}$ capped with $150 \mathrm{~nm} \mathrm{Ag}\left(10 \mathrm{Al}_{2} \mathrm{O}_{3}-150 \mathrm{Ag}\right)$. As shown in Figure S5, without $\mathrm{Al}_{2} \mathrm{O}_{3}$ gap, the AgNRs-150Ag film looks similar to bare AgNRs, with a little increase in nanorod length; the $10 \mathrm{Al}_{2} \mathrm{O}_{3}-150 \mathrm{Ag}$ substrate produces many nanoparticles on $\mathrm{Si}$ surface instead of nanorods. The SERS intensities on $\mathrm{AgNRs}-\mathrm{Al}_{2} \mathrm{O}_{3}-\mathrm{Ag}$ arrays are much higher than those obtained 
on AgNRs-150Ag and $10 \mathrm{Al}_{2} \mathrm{O}_{3}-150 \mathrm{Ag}$, as well as their intensity sum. These results manifest that without $\mathrm{Al}_{2} \mathrm{O}_{3}$ gap or underneath $\mathrm{AgNRs}$, the nanocomposite could not generate very strong SERS enhancement. As for the AgNRs- $\mathrm{Al}_{2} \mathrm{O}_{3}$ - $\mathrm{Ag}$ substrate, the intense interaction between $\mathrm{AgNRs}$ and $\mathrm{Ag}$ capping layers gives rise to a huge EM field within the $\mathrm{Al}_{2} \mathrm{O}_{3}$ gap regions, which is crucial for SERS enhancement. Figure 4 presents the FEM modeling results of (a) AgNRs; (b) AgNRs- $10 \mathrm{Al}_{2} \mathrm{O}_{3}$; and (c) AgNRs- $10 \mathrm{Al}_{2} \mathrm{O}_{3}-150 \mathrm{Ag}$, respectively. AgNRs possess intense EM enhancement at the tip and side of nanorods, while the EM field at the tip of $\mathrm{AgNRs}-10 \mathrm{Al}_{2} \mathrm{O}_{3}$ decreases slightly after $\mathrm{Al}_{2} \mathrm{O}_{3}$ capping. After further Ag deposition of $150 \mathrm{~nm}$, there are evident "hot spots" at the gap between the AgNRs and the Ag capping layer, leading to stronger EM enhancement at the tip and side of this heterojunction structure. This simulation result suggests that the $\mathrm{AgNRs}-10 \mathrm{Al}_{2} \mathrm{O}_{3}-150 \mathrm{Ag}$ array is a superior platform for maximizing the SERS performance.
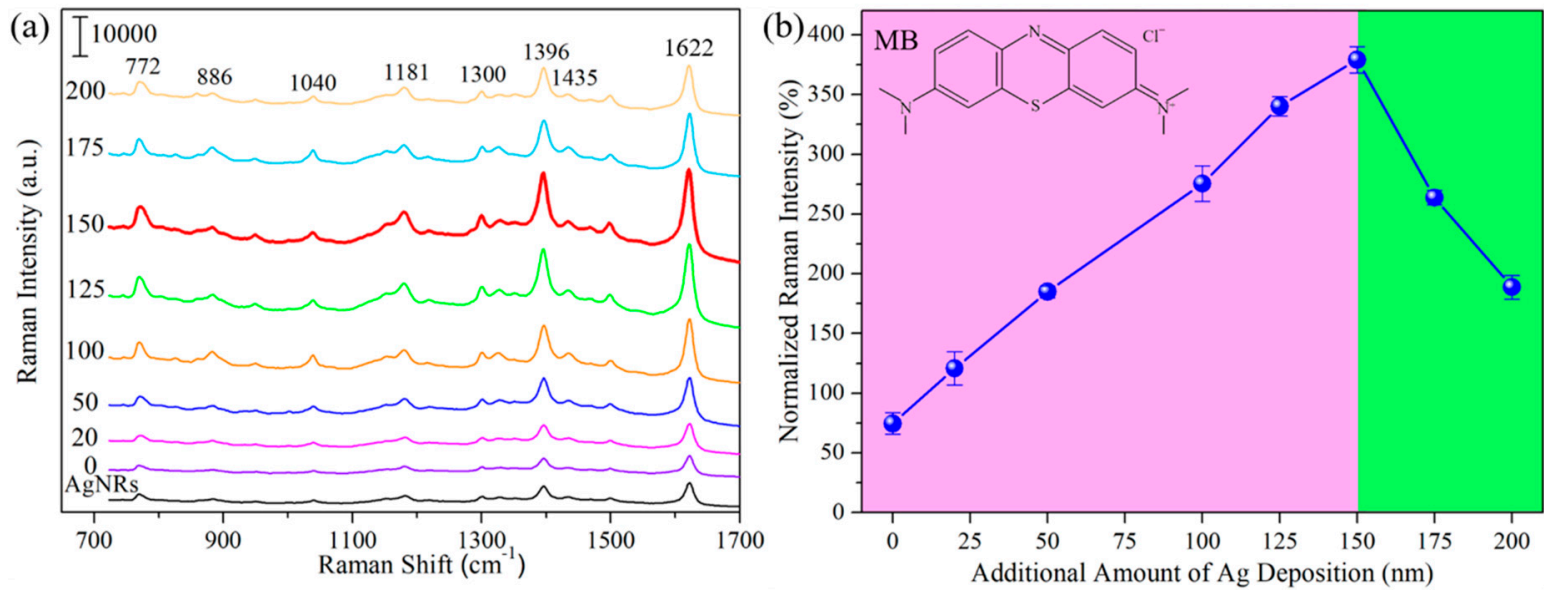

Figure 3. (a) SERS spectra of $1 \times 10^{-6} \mathrm{M} \mathrm{MB}$ on bare AgNRs, and AgNRs- $\mathrm{Al}_{2} \mathrm{O}_{3}-\mathrm{Ag}$ arrays with additional Ag deposition of 0, 20, 50, 100, 125, 150, 175, and $200 \mathrm{~nm}$; marked as AgNRs and the thickness of additional Ag deposition. (b) Raman intensity at $1622 \mathrm{~cm}^{-1}$, normalized with respect to that on bare AgNRs, as a function of the additional thickness of Ag deposition.
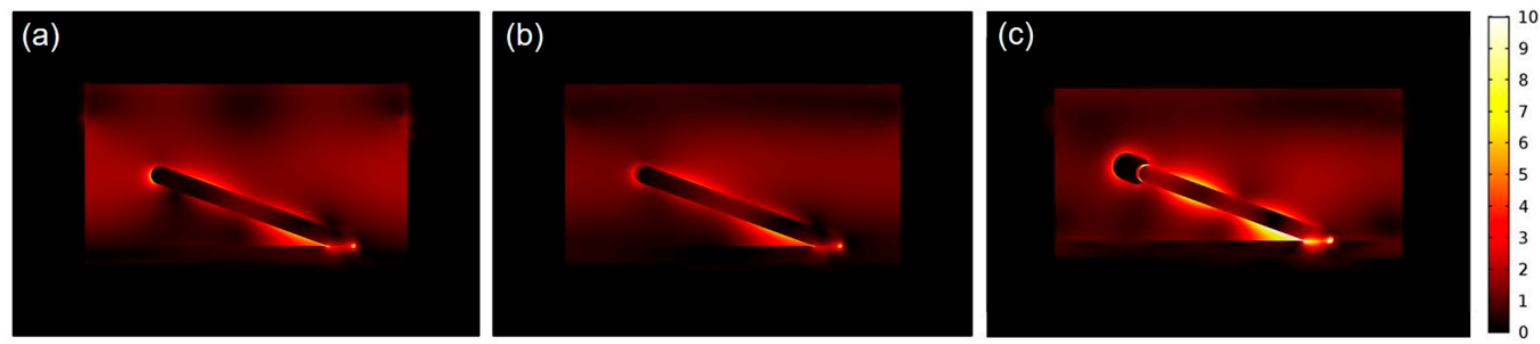

Figure 4. Localized electric field intensity distributions (indicated by the color bar) of (a) AgNRs, (b) AgNRs- $10 \mathrm{Al}_{2} \mathrm{O}_{3}$; and (c) AgNRs- $10 \mathrm{Al}_{2} \mathrm{O}_{3}-150 \mathrm{Ag}$, respectively.

After discussing the optimization of the proposed substrates, we now examine the SERS efficiency and quantification capacity of the designed heterojunctions. Taking $\mathrm{AgNRs}-\mathrm{Al}_{2} \mathrm{O}_{3}-\mathrm{Ag}$ arrays with $150 \mathrm{~nm}$ additional Ag as the substrate, Figure 5a shows the SERS spectra of MB molecules of various concentrations, and Figure $5 \mathrm{~b}$ shows the Raman peak intensity at $1622 \mathrm{~cm}^{-1}$ as a function of the concentration from $1 \times 10^{-10} \mathrm{M}$ to $1 \times 10^{-6} \mathrm{M}$. Even at the concentration of $1 \times 10^{-10} \mathrm{M}$, the Raman signal is clearly measurable and follows the linear dependence on concentration. The peak intensity increases linearly with concentration from $1 \times 10^{-10} \mathrm{M}$ to $1 \times 10^{-8} \mathrm{M}$. The limit of detection (LOD) of MB is about $9.3 \times 10^{-11} \mathrm{M}$ based on a signal-to-background ratio of $\mathrm{S} / \mathrm{N}=3$. At higher concentrations, the intensity increases slowly due to the saturated adsorption. As described in the Supporting Information, the SERS 
enhancement factor reaches $1.3 \times 10^{8}$, which is comparable to the best reported values of AgNRs-based

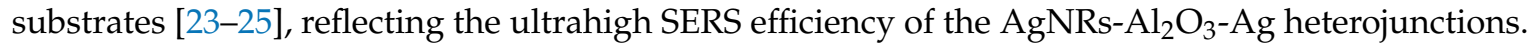
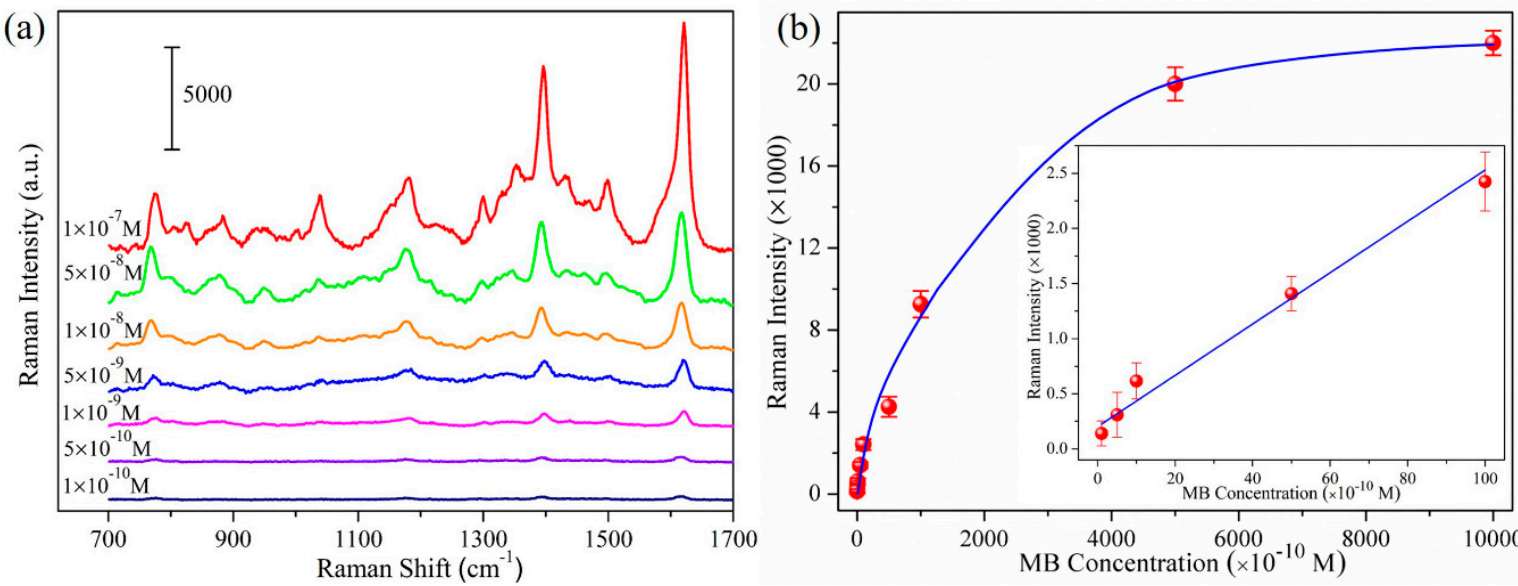

Figure 5. (a) SERS spectra of MB molecules on $\mathrm{AgNRs}-\mathrm{Al}_{2} \mathrm{O}_{3}-\mathrm{Ag}$ substrates with $150 \mathrm{~nm}$ additional $\mathrm{Ag}$; the thickness of MB molecules is marked by each spectrum; (b) Raman peak intensity at $1622 \mathrm{~cm}^{-1}$ as a function of $\mathrm{MB}$ concentrations, inserted: $1622 \mathrm{~cm}^{-1}$ peak intensity from $1 \times 10^{-10} \mathrm{M}$ to $1 \times 10^{-8} \mathrm{M}$.

Having established the high sensitivity of $\mathrm{AgNRs}-\mathrm{Al}_{2} \mathrm{O}_{3}-\mathrm{Ag}$ arrays with $150 \mathrm{~nm}$ additional $\mathrm{Ag}$, we now examine their thermal stability upon annealing. Figure 6 shows the reflectivity of the AgNRs- $\mathrm{Al}_{2} \mathrm{O}_{3}-\mathrm{Ag}$ arrays as a function of the annealing temperature [16]. As expected, the $\mathrm{Al}_{2} \mathrm{O}_{3}$ capping layer still serves the purpose of slowing down the surface diffusion so as to increase the thermal stability up to $200{ }^{\circ} \mathrm{C}$. In comparison with the morphology in Figure $2 \mathrm{c}$, the annealing at $150{ }^{\circ} \mathrm{C}$ hardly changed the morphology and reflectivity. Although annealing at $200^{\circ} \mathrm{C}$ leads to visible coarsening, the arrays remain separate and the reflectivity remains unchanged. As for bare AgNRs, they melted completely at $200^{\circ} \mathrm{C}$ and experienced a substantial SERS enhancement degradation of $\sim 90 \%$ once the temperature went beyond $100{ }^{\circ} \mathrm{C}$ [12]. Therefore, they were not feasible for high-temperature sensing.

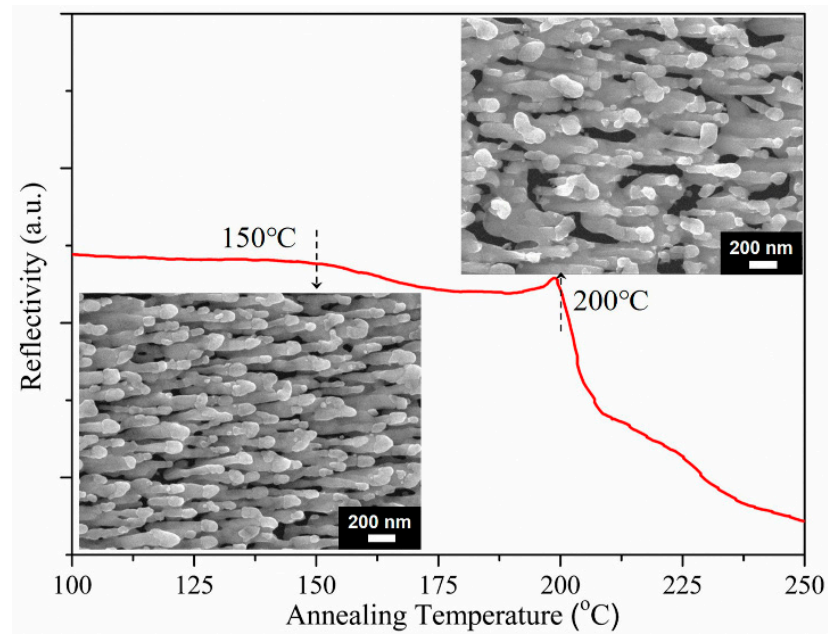

Figure 6. Reflectivity of the AgNRs- $\mathrm{Al}_{2} \mathrm{O}_{3}-\mathrm{Ag}$ arrays as a function of annealing temperature; the insets are SEM images of arrays after annealing at $150{ }^{\circ} \mathrm{C}$ (lower left) and $200^{\circ} \mathrm{C}$ (upper right), respectively.

Finally, as an application, we investigate the reorientation process of 4-tBBM molecules on this unique AgNRs- $\mathrm{Al}_{2} \mathrm{O}_{3}$ - $\mathrm{Ag}$ nanostructure. We first collected the SERS signals of 4-tBBM molecules on the substrate surface at room temperature, and then heated the analyte-adsorbed substrate at $150{ }^{\circ} \mathrm{C}$ for $5 \mathrm{~min}$, followed by measuring the SERS spectra again. Figure 7a presents the SERS spectra 
of 4-tBBM adsorbed on AgNRs- $\mathrm{Al}_{2} \mathrm{O}_{3}-\mathrm{Ag}$ before and after annealing. At room temperature, there are prominent SERS peaks at 1108 and $1192 \mathrm{~cm}^{-1}$ (the vibration of the phenyl ring), $1227 \mathrm{~cm}^{-1}$ (the wagging of methylene groups) and $1608 \mathrm{~cm}^{-1}$ (8a mode) [27]. Upon heating to $150{ }^{\circ} \mathrm{C}$, the SERS intensities at 1108 and $1192 \mathrm{~cm}^{-1}$ increased and the signal at $1227 \mathrm{~cm}^{-1}$ remained steady. Of particular interest is that the peak at $1608 \mathrm{~cm}^{-1}$ shifted to $1599 \mathrm{~cm}^{-1}$. These intensity and peak position variations imply that the orientation changes of 4-tBBM molecules on the substrate surface during heating. To be specific, the intensity increase at 1192 and $1108 \mathrm{~cm}^{-1}$ of in-plane modes of 4-tBBM suggests that the angle between the phenyl ring and the surface normal of the substrate decreases upon annealing [27], a schematic diagram of which is shown in Figure $7 \mathrm{~b}$. The peak shift from 1608 to $1599 \mathrm{~cm}^{-1}$ also verifies such a transition. Therefore, thermal energy accelerates the molecular vibration and drives 4-tBBM to rearrange to a more stable orientation. $\mathrm{AgNRs}-\mathrm{Al}_{2} \mathrm{O}_{3}-\mathrm{Ag}$ thus holds great potential to determine the orientation and conformation of interfacial molecules on SERS substrates.

(a)

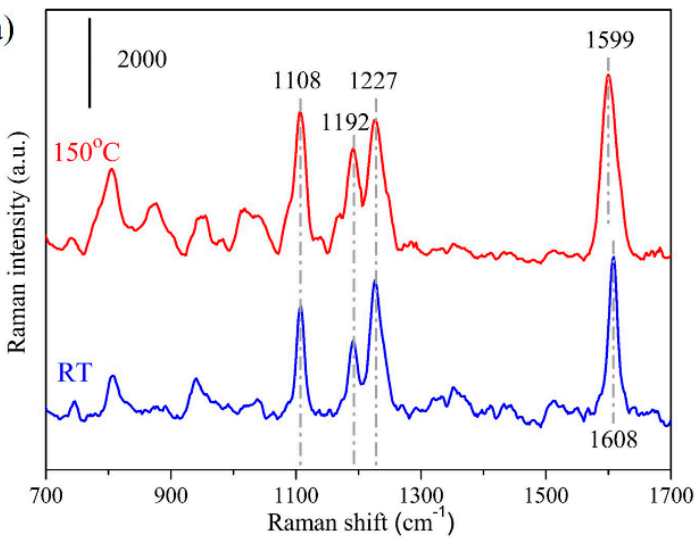

(b)

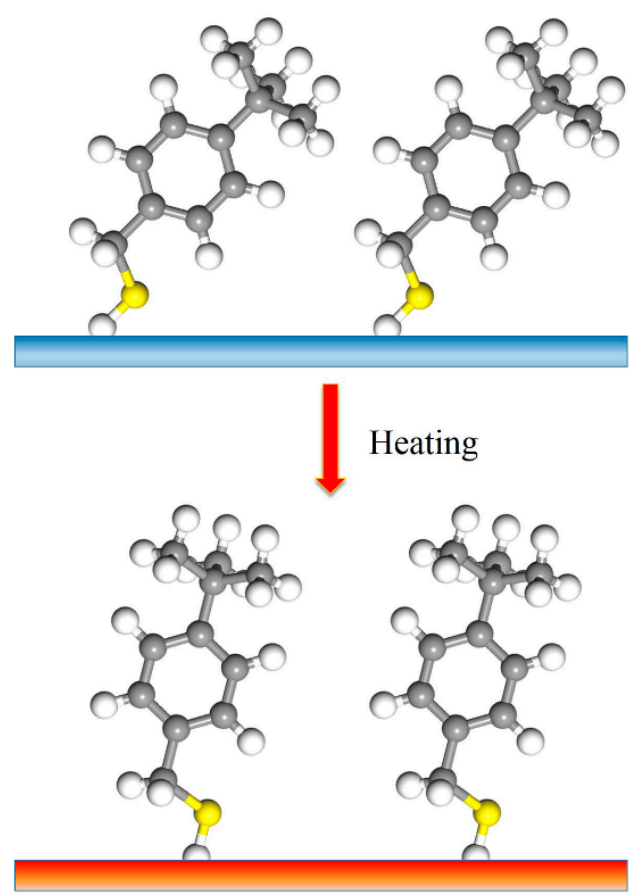

Figure 7. (a) SERS spectra of $1 \times 10^{-6} \mathrm{M}$ 4-tBBM molecules adsorbed on $\mathrm{AgNRs}-\mathrm{Al}_{2} \mathrm{O}_{3}-\mathrm{Ag}$ arrays with $150 \mathrm{~nm}$ additional $\mathrm{Ag}$ deposition, at room temperature (RT) and upon heating at $150{ }^{\circ} \mathrm{C}$ for $5 \mathrm{~min}$. (b) Schematic of 4-tBBM molecule reorientation process upon heating. 


\section{Conclusions}

In conclusion, through the design of nanoscale heterojunctions, we have developed AgNRs-based SERS substrates that (1) have about $400 \%$ times the sensitivity of pure AgNRs and (2) are thermally stable up to $200{ }^{\circ} \mathrm{C}$. The $\mathrm{AgNRs}-\mathrm{Al}_{2} \mathrm{O}_{3}-\mathrm{Ag}$ heterojunctions are prepared facilely using physical vapor deposition under the glancing angle incidence. The optimal thickness of additional Ag deposition on top of $\mathrm{AgNRs}-\mathrm{Al}_{2} \mathrm{O}_{3}$ is $150 \mathrm{~nm}$. To demonstrate the impacts of the design, we have shown that the AgNRs- $\mathrm{Al}_{2} \mathrm{O}_{3}-\mathrm{Ag}$ arrays have an ultrahigh SERS enhancement factor on the order of $10^{8}$. Additionally, the heterojunction arrays allow the characterization of reorientation processes of interfacial 4-tBBM molecules on the substrate upon heating. The AgNRs- $\mathrm{Al}_{2} \mathrm{O}_{3}-\mathrm{Ag}$ arrays, with both superior SERS sensitivity and thermal stability, hold great potential for real-world SERS applications.

Supplementary Materials: The following are available online at http://www.mdpi.com/2079-4991/9/6/830/s1,

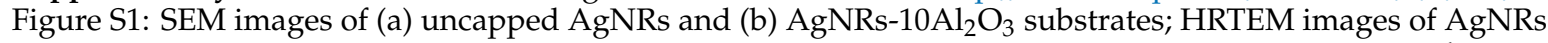
capped with $\mathrm{Al}_{2} \mathrm{O}_{3}$ layers of (c) 8, (d) 10 and (e) $20 \mathrm{~nm}$, respectively. Figure S2: (a) SERS spectra of $1 \times 10^{-6} \mathrm{M} \mathrm{MB}$ adsorbed on bare AgNRs and on AgNRs- $\mathrm{Al}_{2} \mathrm{O}_{3}$ substrates with different capping thickness; (b) The normalized intensities of $1622 \mathrm{~cm}-1$ Raman peak of $1 \times 10^{-6} \mathrm{M} \mathrm{MB}$ molecules as a function of the $\mathrm{Al}_{2} \mathrm{O}_{3}$ thickness of different AgNRs- $\mathrm{Al}_{2} \mathrm{O}_{3}$ substrates. Figure S3: SEM images of $\mathrm{AgNR}$ and different $\mathrm{AgNRs}-\mathrm{Al}_{2} \mathrm{O}_{3}$ substrates after annealing at $150{ }^{\circ} \mathrm{C}$ and $200{ }^{\circ} \mathrm{C}$ for $15 \mathrm{~min}$. Figure S4: The reflectivity changes of different $\mathrm{AgNRs}-\mathrm{Al}_{2} \mathrm{O}_{3}$ substrates upon annealing from $100{ }^{\circ} \mathrm{C}$ to $250{ }^{\circ} \mathrm{C}$. Figure S5: SEM images of (a) AgNRs-150Ag and (b) $10 \mathrm{Al}_{2} \mathrm{O}_{3}-150 \mathrm{Ag}$ substrates; (c) SERS spectra of $1 \times 10^{-6} \mathrm{M} \mathrm{MB}$ molecules adsorbed on AgNRs-10Al $\mathrm{O}_{3}-150 \mathrm{Ag}$, AgNRs-150Ag and $10 \mathrm{Al}_{2} \mathrm{O}_{3}-150 \mathrm{Ag}$ substrates, separately.

Author Contributions: Conceptualization, H.H. and L.M.; methodology, Z.Z.; software, J.W.; validation, Y.F. and X.L.; formal analysis, L.M.; investigation, Z.Z. and Y.F.; resources, L.M.; data curation, J.W. and X.L.; writing—original draft preparation, L.M.; writing—review and editing, H.H.; visualization, L.M.; supervision, Z.Z. and H.H.; project administration, Z.Z. and H.H.; funding acquisition, Z.Z. and H.H.

Funding: This research was funded by the National Natural Science Foundation of China (51531006); the China Postdoctoral Science Foundation (2018M641189); the Fundamental Research Funds for the Central Universities (FRF-TP-18-090A1). Author Hanchen Huang acknowledges the sponsorship of US Department of Energy Office of Basic Energy Science (DE-SC0014035).

Conflicts of Interest: The authors declare no conflict of interest.

\section{References}

1. Fateixa, S.; Nogueira, H.; Trindade, T. Hybrid nanostructures for SERS: Materials development and chemical detection. Phys. Chem. Chem. Phys. 2015, 17, 21046-21071. [CrossRef] [PubMed]

2. Ma, Y.; Huang, Z.; Li, S.; Zhao, C. Surface-enhanced Raman spectroscopy on self-assembled Au nanoparticles arrays for pesticides residues multiplex detection under complex environment. Nanomaterials 2019, 9, 426. [CrossRef] [PubMed]

3. Sitjar, J.; Liao, L.; Lee, H.; Liu, B.; Fu, W. SERS-active substrate with collective amplification design for trace analysis of pesticides. Nanomaterials 2019, 9, 664. [CrossRef] [PubMed]

4. Kalachyova, Y.; Erzina, M.; Postnikov, P.; Svorcik, V.; Lyutakov, O. Flexible SERS substrate for portable Raman analysis of biosamples. Appl. Surf. Sci. 2018, 458, 95-99. [CrossRef]

5. Chen, H.; Lin, M.; Wang, C.; Chang, Y.; Gwo, S. Large-scale hot spot engineering for quantitative SERS at the single-molecule scale. J. Am. Chem. Soc. 2015, 137, 13698-13705. [CrossRef] [PubMed]

6. Liu, K.; Bai, Y.; Zhang, L.; Yang, Z.; Fan, Q.; Zheng, H.; Yin, Y.; Gao, C. Porous Au-Ag nanospheres with high-density and highly accessible hotspots for SERS analysis. Nano Lett. 2016, 16, 3675-3681. [CrossRef] [PubMed]

7. Yang, C.; Zhang, C.; Huo, Y.; Jiang, S.; Qiu, H.; Xu, Y.; Li, X.; Man, B. Shell-isolated graphene@Cu nanoparticles on graphene@Cu substrates for the application in SERS. Carbon 2016, 98, 526-533. [CrossRef]

8. Bottani, C.; Bassi, A.; Tanner, B.; Stella, A.; Tognini, P.; Cheyssac, P.; Kofman, R. Melting in metallic Sn nanoparticles studied by surface Brillouin scattering and synchrotron-x-ray diffraction. Phys. Rev. B 1999, 59, 15601-15604. [CrossRef]

9. Pan, C.; Zhang, Z.; Su, X.; Zhao, Y.; Liu, J. Characterization of Fe nanorods grown directly from submicron-sized iron grains by thermal evaporation. Phys. Rev. B 2004, 70, 233404. [CrossRef] 
10. Bachenheimer, L.; Elliott, P.; Stagon, S.; Huang, H. Enhanced thermal stability of Ag nanorods through capping. Appl. Phys. Lett. 2014, 105, 213104. [CrossRef]

11. Mai, F.; Yang, K.; Liu, Y.; Hsu, T. Improved stabilities on surface-enhanced Raman scattering-active $\mathrm{Ag} / \mathrm{Al}{ }_{2} \mathrm{O}_{3}$ films on substrates. Analyst 2012, 137, 5906-5912. [CrossRef] [PubMed]

12. Ma, L.; Zhang, Z.; Huang, H. Design of Ag nanorods for sensitivity and thermal stability of surface-enhanced Raman scattering. Nanotechnology 2017, 28, 405602. [CrossRef] [PubMed]

13. John, J.; Mahurin, S.; Dai, S.; Sepaniak, M. Use of atomic layer deposition to improve the stability of silver substrates for in situ, high-temperature SERS measurements. J. Raman. Spectrosc. 2009, 41, 4-11. [CrossRef]

14. Mahurin, S.; John, J.; Sepaniak, M.; Dai, S. A reusable surface-enhanced Raman scattering (SERS) substrate prepared by atomic layer deposition of alumina on a multi-layer gold and silver film. Appl. Spectrosc. 2011, 65, 417-422. [CrossRef] [PubMed]

15. Ma, L.; Huang, Y.; Hou, M.; Xie, Z.; Zhang, Z. Ag nanorods coated with ultrathin $\mathrm{TiO}_{2}$ shells as stable and recyclable SERS substrates. Sci. Rep. 2015, 5, 15442. [CrossRef]

16. Ma, L.; Wu, H.; Huang, Y.; Zou, S.; Li, J.; Zhang, Z. High-performance real-time SERS detection with recyclable Ag nanorods@ $\mathrm{HfO}_{2}$ substrates. ACS Appl. Mater. Interfaces 2016, 8, 27162-27168. [CrossRef] [PubMed]

17. Masango, S.; Hackler, R.; Henry, A.; McAnally, M.; Schatz, G.; Stair, P.; Van Duyne, R. Probing the chemistry of alumina atomic layer deposition using operando surface-enhanced Raman spectroscopy. J. Phys. Chem. C 2016, 120, 3822-3833. [CrossRef]

18. Zhang, J.; Zhang, D.; Shen, D. Orientation study of atactic poly(methyl methacrylate) thin film by SERS and RAIR spectra. Macromolecules 2002, 35, 5140-5144. [CrossRef]

19. Formo, E.; Wu, Z.; Mahurin, S.; Dai, S. In situ high temperature surface enhanced Raman spectroscopy for the study of interface phenomena: Probing a solid acid on alumina. J Phys. Chem. C 2011, 115, 9068-9073. [CrossRef]

20. Willets, K.; Van Duyne, R. Localized surface plasmon resonance spectroscopy and sensing. Annu. Rev. Phys. Chem. 2007, 58, 267-297. [CrossRef]

21. Lai, Y.; Chen, S.; Hayashi, M. Mesostructured arrays of nanometer-spaced gold nanoparticles for ultrahigh number density of SERS hot spots. Adv. Funct. Mater. 2014, 24, 2544-2552. [CrossRef]

22. Shiohara, A.; Wang, Y.; Liz-Marzán, L. Recent approaches toward creation of hot spots for SERS detection. J. Photochem. Photobiol. C 2014, 21, 2-25. [CrossRef]

23. Han, C.; Yao, Y.; Wang, W.; Qu, L.; Bradley, L.; Sun, S.; Zhao, Y. Rapid and sensitive detection of sodium saccharin in soft drinks by silver nanorod array SERS substrates. Sens. Actuators B Chem. 2017, 251, 272-279. [CrossRef]

24. Liu, Y.; Chu, H.; Zhao, Y. Silver nanorod array substrates fabricated by oblique angle deposition: morphological, optical, and SERS characterizations. J. Phys. Chem. C 2010, 114, 8176-8183. [CrossRef]

25. Driskell, J.; Shanmukh, S.; Liu, Y.; Chaney, S.; Tang, X.; Zhao, Y.; Dluhy, R. The use of aligned silver nanorod arrays prepared by oblique angle deposition as surface enhanced Raman scattering substrates. J. Phys. Chem. C 2008, 112, 895-901. [CrossRef]

26. Xiao, G.; Man, S. Surface-enhanced Raman scattering of methylene blue adsorbed on cap-shaped silver nanoparticles. Chem. Phys. Lett. 2007, 447, 305-309. [CrossRef]

27. Tong, L.; Zhu, T.; Liu, Z. Laser irradiation induced spectral evolution of the surface-enhanced Raman scattering (SERS) of 4-tert-butylbenzylmercaptan on gold nanoparticles assembly. Sci. China Ser. B 2007, 50, 520-525. [CrossRef]

(C) 2019 by the authors. Licensee MDPI, Basel, Switzerland. This article is an open access article distributed under the terms and conditions of the Creative Commons Attribution (CC BY) license (http://creativecommons.org/licenses/by/4.0/). 